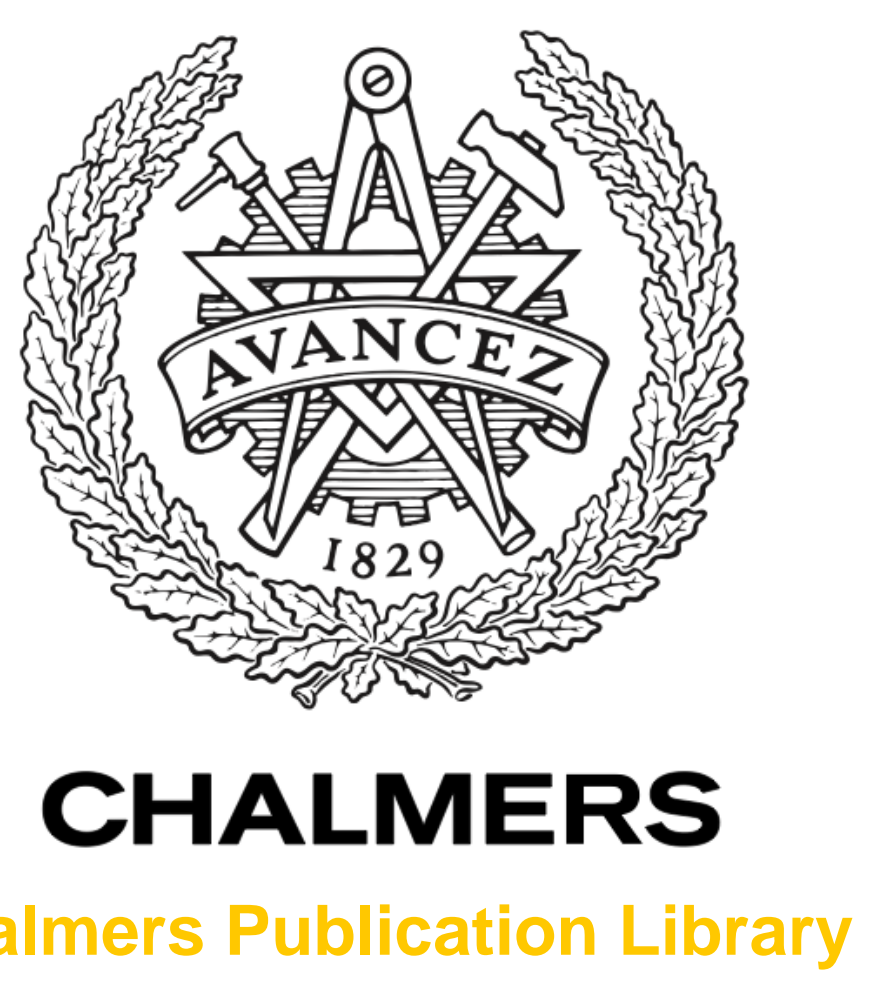

\title{
Introducing Robust Design in Product Development Learning from an initiative at Volvo
}

This document has been downloaded from Chalmers Publication Library (CPL). It is the author's version of a work that was accepted for publication in:

Total Quality Management and Business Excellence (ISSN: 1478-3363)

Citation for the published paper:

Fazl Mashhadi, A. ; Alänge, S. ; Roos, L. (2012) "Introducing Robust Design in Product Development Learning from an initiative at Volvo". Total Quality Management and Business Excellence, vol. 23(9-10), pp. 1191-1205.

http://dx.doi.org/10.1080/14783363.2012.728847

Downloaded from: http://publications.lib.chalmers.se/publication/164703

Notice: Changes introduced as a result of publishing processes such as copy-editing and formatting may not be reflected in this document. For a definitive version of this work, please refer to the published source. Please note that access to the published version might require a subscription. 


\title{
Introducing Robust Design in Product Development
}

\author{
Learning from an initiative at Volvo
}

\author{
Azadeh Fazl Mashhadi ${ }^{1}$ \\ Sverker Alänge ${ }^{2}$ \\ Lars-Uno Roos ${ }^{3}$
}

\begin{abstract}
Robust design has a large potential to contribute to product and process improvements providing increased customer value. However, it has shown to be difficult to obtain these benefits in practice. This study aims to evaluate and learn from an initial approach in introducing robust design within the Volvo Group. It is based on three pilot cases within the product development organization of a business unit. Data were collected through formal interviews and informal dialogues with pilot participants, supplemented by existing documentation of the pilot cases. The main finding was that a robust design initiative, characterized by 'tool-pushing' and with a predefined solution introduced by an external consultant, faced many obstacles and could not create a sustainable result. Instead, it was found that there is a need of involving the engineers and creating a learning culture in which robust design principles can become a natural part of work practices. This study identified six obstacles for the success of the initiative, which were perceived as learning points for a broader application of robust design at the company. This underscores that robust design initiatives can also be hampered by similar types of obstacles that have been identified in research of other change processes.
\end{abstract}

Keywords: change management, resistance to change, localizing, middle management, product development, robust design method, P-diagram, Pugh matrix

\section{Introduction}

Robust design refers to decreasing the unwanted variation of product performances through considering the sources of variation already from early phases of product development. Any method or strategy with this purpose could be considered under the robust design concept, e.g. the Robust Design (RD) method (Taguchi, 1986). There are many examples of the benefits that result from the application of robust design, but also many examples of companies having difficulty in making robust design a standard practice within product development (Hasenkamp, 2009).

\footnotetext{
${ }^{1}$ PhD student at Chalmers University of Technology, Dept. of Technology Management and Economics, Division of Quality Sciences, SE-412 96 Gothenburg and Lean Program Manager at Volvo Penta AB. Email: azadeh.fazl.mashhadi@chalmers.se

${ }^{2}$ Corresponding author: Associate professor, Chalmers University of Technology, Dept. of Technology Management and Economics, Division of Quality Sciences, SE-412 96 Gothenburg. Email: sverker.alange@chalmers.se

${ }^{3} \mathrm{PhD}$, Senior manager, application of Lean approaches in product development, Volvo Technology AB. Email: lars-uno.roos@volvo.com
} 
The Volvo Group ${ }^{4}$ has been successful in designing and marketing its products over many years. However, the corporation recognized that in order to sustain its success it needed to integrate robust design as a standard practice within product development. But the question is how to do this. The Volvo Group has been testing a number of approaches to introduce robust design, and this article presents an evaluation of one such approach, referred to as the RD initiative. The approach began in 2004 when an experienced external consultant was hired, to drive an ambitious initiative within one business unit in the Volvo Group. The aim was to introduce and apply the Taguchi RD method in three 'pilot projects'. However, it was observed that the application of the RD initiative in this unit was not appreciated by the product development engineers at the first trial. As a result, the company decided that before continuing with additional efforts, it would be good to reflect upon and learn from this relatively unsuccessful trial.

This paper presents the results of reflecting upon the experience of the first trial and provides some learning points. The learning includes identification of obstacles to the diffusion of the RD method, and a discussion of possible measures for successful application of robust design (Section 4-5). The insights from this first trial have been used in the design of later initiatives within the Volvo Group.

\section{Methodology}

This paper is based on a study of an RD initiative within a business unit ( 4,000 employees) of the Volvo Group. The initiative includes three pilot cases within the product development organization.

A case study approach was used to investigate the application of the RD method within the company (e.g. Merriam, 1988; Yin, 2003). This investigation started after the termination of the RD initiative. Data were collected through 9 semi-structured interviews with employees who had been involved in the planning and/or participated in the implementation of the RD initiative (2 top managers, 3 quality managers, 1 project manager and 3 development engineers). The interviews were supplemented by informal dialogues with the participants in the RD initiative. In addition, secondary data were used, such as documents and archival records (e.g. protocols), an evaluation questionnaire, presentation material and consultants' reports from the initiative. The analysis was initially conducted directly on the basis of the empirical data, guided by the research question: What were the obstacles affecting the introduction of the Robust Design Method in product development processes? Then the empirical findings were compared to relevant literature, i.e. the analysis was conducted according to an 'abductive' approach (Dubois \& Gadde, 2002).

The first and the third authors are part of the Volvo Group and involved in the initiatives to implement robust design. This has provided them with excellent access to internal company data, but naturally also increases the risk of 'going native'. Hence, the second author, from an external university position, has had a role of examining and discussing the findings from an outsider perspective. However, in the case of this first initiative, the lead author was not directly involved in the pilot

\footnotetext{
${ }^{4}$ The Volvo Group includes companies producing trucks, buses, construction equipment and marine \& airplane engines. Volvo was founded in 1927.
} 
projects, and thus the evaluation has been conducted from various positions on the insider-outsider scale (de Guerre, 2002; Coghlan \& Brannick, 2005).

\section{Previous Research}

This section comments upon the limited use of robust design in practice (3.1), presents research focused on measures to increase acceptance of robust design in industry (3.2) and concludes with theory on resistance to change (3.3).

\subsection{Limited use of robust design in industry}

The approach developed by Dr. Genichi Taguchi, the Robust Design method (RD method), can be seen as pioneering in practical industry application (Phadke, 1989). Taguchi's starting point was that any decrease in product/system quality leads to customer dissatisfaction ${ }^{5}$ and therefore, the focus should be on 'building in' quality by designing for 'right on target' specifications (best values). The aim was to design products and processes which are insensitive to noise factors (sources of unwanted variation) under actual, real-life conditions with the help of simplified statistical techniques (Taguchi 1986). The RD method was launched in Japan in the 1970s, but its use among Japanese companies was limited. The method first gained wider recognition in the United States in the 1980s and was then re-imported to Japan during the 1990s; however, with the exception of a few companies, e.g. Fuji Xerox, the RD method failed to be extensively applied (Hino, 2006).

A major part of the research literature on robust design is within a tool-based research tradition and has been focused on developing statistical techniques for identifying robust design solutions (Hasenkamp et al. 2009). However, robust design, as a general concept, has gradually become popular also in product development literature (e.g. Araujo et al., 1996; Ulrich \& Eppinger, 2004). Despite the popularity of the robust design concept in the research literature, the application of the robust design methodologies in industry does not seem to be very widespread (Thornton et al., 2000; Antony, 2002; Gremyr et al., 2003; Arvidsson et al., 2003; Saitoh et al., 2003).

\subsection{Approaches to increase acceptance of robust design}

The gap between a growing research interest and limited practical application has inspired researchers to search for ways of increasing the acceptance of the concept of robust design in industry. An awareness of variation and robustness has been seen as an important driver for implementing the robust design methodology (RDM). ${ }^{6}$ Hasenkamp et al. (2007) provided review questions for each design phase in order to increase the awareness of variation and thinking in terms of robustness. They also presented guidelines for implementing the RDM in a generic product development process by providing recommendations for which RD tools are suitable for different phases of the PD process.

\footnotetext{
${ }^{5}$ This is expressed in Taguchi's 'quality loss function' that states that any deviation from the target value leads to a quadratic loss in quality (or customer satisfaction).

${ }^{6} \mathrm{RDM}$ is referred to as any systematic effort (statistical or non-statistical) to achieve insensitivity to noise factors (the sources of variation) (Arvidsson \& Gremyr, 2008).
} 
Yet a further step to increase acceptance has been to utilize the 'practices' concept in order to create a link between 'general principles' behind the RDM and the use of 'tools'. Arvidsson and Gremyr (2008) identified the underlying principles as: awareness of variation, insensitivity to noise factors, and continuous applicability (i.e. that robust design is applicable in all phases of a product development process). Based on a literature review, Hasenkamp et al. (2009) aimed at identifying the missing link between the principles and the tools in their model, i.e. the 'practices'. For the 'awareness of variation' they identified three practices: focusing on customers (meaning identifying key product characteristics that can be translated into measurable quality characteristics), identifying and understanding noise factors, and checking assumptions. 'Insensitivity to noise factors' was also linked to three practices: exploiting nonlinearities and interactions, designing for insensitivity to noise factors, and using conventional design rules. Concerning the last principle, 'continuous applicability', no specific practice was identified. Instead, Hasenkamp et al. (2009, p.653) pointed out that "this principle rather concerns organisational issues, such as how RDM is implemented and organised in a company." However, they provide references to the importance of making robust design part of the standard design procedures and in the mind-sets of all product developers (Mörup, 1993); and of not forcing engineers to make use of tools - instead, the issues should be explained to the engineers followed by providing them with appropriate RDM tools, in order to keep the resistance within a limit (Saitoh et al., 2003).

In an empirical study, Gremyr and Hasenkamp (2011) continued to study the difficulties that a company faces when trying to introduce RDM. They identified a gap between principles and tool use and suggested that this gap could be bridged by practices. However, in their discussion they primarily elaborate upon the role of an RDM mentor as a solution to bridge the gap, i.e. an organizational solution, which is outside their framework of practices. Discussing 'Views on robust design methodology' they also comment that their interviewees had referred to both personal and general reasons as barriers for employees to proceed in the RDM implementation. Common personal factors include backgrounds, experiences, interest in RDM, inclinations, working preferences and access to software products. General factors mentioned include lack of resources (time and money), that RDM was applied too late, and trusting one's own experience more than the RDM tools. Although mentioned, these types of factors were not in focus in Gremyr and Hasenkamp's (2011) analysis.

However, what will be shown in our empirical study of the implementation of Volvo's RD method is that most obstacles identified are to be found in these categories. ${ }^{7}$ Hence, the next section will focus on theory related to resistance and change.

\footnotetext{
${ }^{7}$ Moosa and Sajid (2010, p.754) commented that "Even the most scholarly literature available is focused on principles, phenomena, and techniques of Six Sigma. Consequently, social aspects of implementation are underestimated, undermined or undiscovered during the implementation phase.”

${ }^{8}$ Dahlgaard-Park (2011) observed that both organisations and many theoreticians focus on mechanistic and rational aspects of organisations, including believing "that measurements can cover every aspect of organisational improvement” instead of "the more 'softer' aspects such as organisational culture, values, people motivation, training \& education, etc.”
} 


\subsection{Resistance to Change}

There are many examples of failed initiatives for change that have been initiated from the top (Beer et al. 1990). Not least, it has proved very hard to change successful organizations, leading to a pattern of success followed by failure and innovation followed by inertia (Tushman \& O’Reilly III, 1997). Most change programs initiated from the top in organizations face resistance from employees who seem unwilling to accept a change. Traditionally, many change theorists start out from this perspective of 'overcoming resistance to change', e.g. Coch and French (1948). Kotter and Schlesinger (1979/2008) pointed at the need for managers to be aware of the four most common reasons for resistance: desire not to lose something of value; misunderstanding of the change; belief that the change does not make sense for the organization; and low tolerance for change. They proposed various ways to align those employees that potentially could resist a change initiative, e.g. through education and communication; participation and involvement; facilitation and support; negotiation and agreement; manipulation and co-optation; and explicit and implicit coercion. However, Dent and Goldberg (1999) claim that a major flaw in many change efforts is the mental model of (and belief in) an inherent resistance to change, which only impedes change efforts.

According to Schein (1996), the resistance to change can be seen as 'learning anxiety', which comes from being afraid to try something new that might be too difficult or that forces one to give up old habits. On the other hand, 'survival anxiety' denotes the anxiety related to being afraid of staying the same, e.g. believing that the company and the job will be lost if there is no change. According to this psychology based theory, change will happen only if the learning anxiety is less than the survival anxiety of staying the same.

According to Argyris et al. (1985), change implementation typically involves learning, a term that refers to reflection on and changing of patterns of thinking and acting among individuals and in groups. Argyris and Schön (1978/1996) framed two different forms of learning: Single-loop learning means the type of learning that takes place within the framework of the present assumptions; Double-loop learning is the result of deeper reflection on fundamental assumptions and may involve radical changes. What the reviewed authors have in common is that they all agree that learning is a core factor for any successful and sustainable change.

\section{The case of the RD initiative in the company}

The RD method was first introduced to Volvo in 1995 when Shin Taguchi (the son of Genichi Taguchi), working as a consultant for the American Supplier Institute, visited the company and presented Taguchi methods. ${ }^{9}$ After this visit, little action took place in this area until 2002, when the top executive management team initiated an investigation of the opportunities to decrease fault frequency and warranty costs. The result of this study showed that the variations in the usage environments of the products were not considered sufficiently during the first design efforts. This neglect might result in unwanted variation of the product performance close to the product

\footnotetext{
${ }^{9}$ Individual managers from Volvo also participated in an external one-day training program with Shin Taguchi called “Introduction to Robust Design using Taguchi Methods”.
} 
launch, and thereby late and costly design loops for correction and higher risk of customer dissatisfaction.

In order to improve the situation, an initiative was launched to establish a systematic and proactive way of working that included the RD method ${ }^{10}$. This first RD initiative was started early in 2004, and it was led and sponsored by the business unit's top management team. The aim of the initiative was to introduce the RD method through creation of success stories as the first run. For this job an experienced international consultant was invited to the company to introduce the RD method using pilot projects. The first RD initiative continued for six months. Unfortunately the organization did not perceive good results from the application of the RD method through this initiative. However, the effort served as an eye-opener and provided input for subsequent improvements. In the section that follows we will describe and provide a deeper analysis of this case.

\subsection{The initiative}

Before the start of the initiative, top management and the consultant together identified three main explicit objectives for the RD initiative: improving the design and development processes to eliminate quality problems and resulting costs; creating pilot projects for robust design; and training project quality managers in robust design. Each pilot project was supposed to have at least five team members: three design engineers, their immediate supervisor, and one project quality manager. The expectation was that the quality managers by participating in the pilot projects would be able to gain sufficient expertise in the RD method to facilitate their projects after the consultant left. In addition it was planned to provide supplementary training to quality managers in order to make them competent enough to be able by themselves to assist projects in implementing the $\mathrm{RD}$ method.

The main roles and activities in the initiative are illustrated in Figure 1.

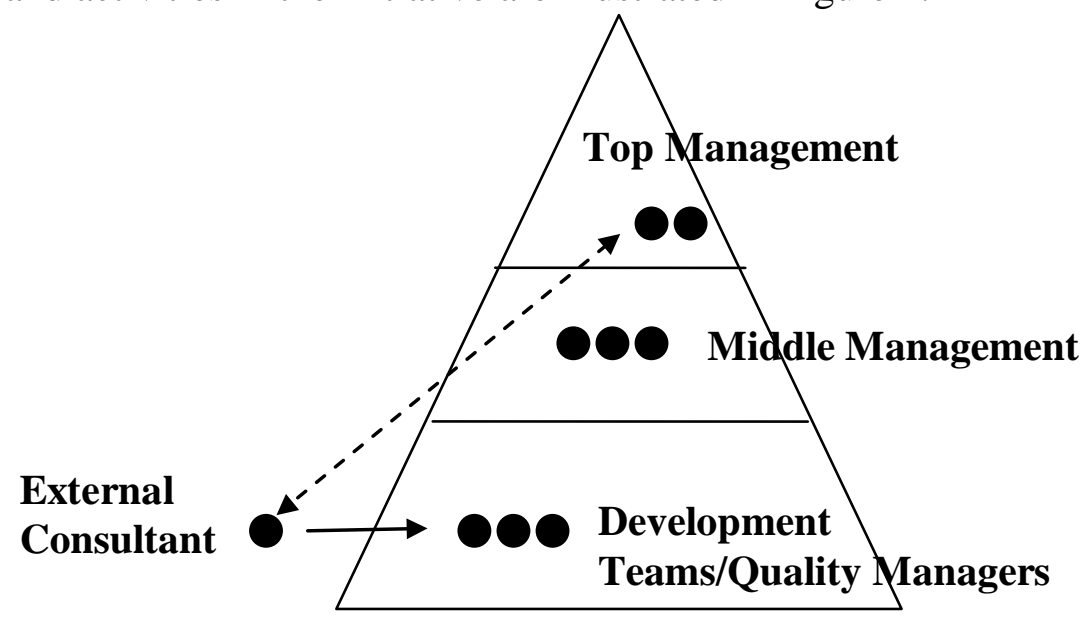

-.-.- Consultancy

Lead and coach

\footnotetext{
${ }^{10}$ The RD method, as referred to in this paper, mainly concerns Taguchi's methods for system, parameter and tolerance design.
} 
As the first step, the consultant suggested that the quality managers should collect information regarding at least ten different proposals for pilot projects and evaluate them based on a questionnaire provided by the consultant. Then they should select three pilot projects and prepare a necessary pilot description based on the evaluation.

After the pilot projects were identified, the consultant met each pilot project team to introduce the RD method and review the steps to be taken. He started to introduce the $\mathrm{RD}$ method through a one-day seminar for some line managers and engineers from the pilot projects, covering the content and tools in the RD method and the software available, and providing examples. After this seminar, the three pilots started.

On this first visit, the consultant directly supported the pilots for two weeks. In order to make the problems clear, he interviewed the pilot team members. After having defined the problems, the consultant explained more about the method for the development teams, and elaborated on how the teams could benefit from the method to improve their product designs. An action plan was also created for each pilot regarding the usage of the RD method's tools ${ }^{11}$. During his stay, some activities regarding the P-diagram ${ }^{12}$ were reported and the consultant helped one pilot project to design a DoE experimental matrix.

After two weeks the consultant left the company, having agreed to continue through net-meetings and e-mails. This decision was taken due to financial restriction of the initiative. The pilots' progress was followed up through net-meetings and e-mails by the consultant, and the pilot projects seemed to be implemented almost according to the plan.

After six months the consultant returned to the company to physically follow up the progress, help with the data analysis and set up the further actions to be taken. It was then realized that the planned activities were not fully integrated into the projects, because the activities were treated as additional jobs parallel to the old way of working. People also complained about doing these double jobs.

In all three cases, Pugh as a tool for concept selection had been utilized; however, it had not been treated as a decision-making tool for the projects, but as a tool to justify an already made decision concerning concepts. The P-diagram had also been used to illustrate the products' functionality. According to the engineers, it helped them to understand the products' functionality, errors and contributing parameters. It also increased the engineers' knowledge about sources of variation and noise factors, which was quite a new step at the company. But the tools had not been integrated into the projects' activities and decision-making processes. As for DoE, it had not been fully applied as planned in any of the pilot projects.

\footnotetext{
${ }^{11}$ These tools included the Pugh concept evaluation and selection of concepts (system design step); the P-diagram for functional analysis; and Design of Experiments (parameter and tolerance design steps).

12 The P-diagram provides a description of a design concept in terms of the signal (input) and response (output) variables, the factors beyond the control of the designer (noise factors) and the factors that can be specified and set (control factors) in order to minimize the noise factors' effect on the response variable, i.e. robust design.
} 
The consultant continued in the company for another week to examine the results of the pilots and to investigate the reasons for the problems. As a consequence he provided a report which included the observations, gaps and further suggestions for how to continue with robust design in the company. This report provided input to the authors' analysis together with their interview data. The outcome of this analysis was that several obstacles to the initiative's success were identified.

\subsection{Findings - the obstacles}

As stated above, the study aims to answer the following research question: What were the obstacles affecting the introduction of the Robust Design Method in product development processes? In the following section we will present the six main obstacles found that were affecting the RD initiative's success.

\section{Set-up of the initiative was unsuitable to affect proud engineers}

Top management set up the RD initiative and middle management supported the selection of pilot projects, while the external consultant took the role of change leader. He worked directly with the development teams to provide them with the required knowledge of the RD method, and to support the implementation in pilot cases. However, the development engineers did not appreciate having an external consultant telling them what to do in their technical areas. In one case a member of a pilot project said more explicitly:

"We have very competent engineers who know the product best. We have already achieved very good results by relying on our engineers' competence. I don't think it was a wise idea asking an external consultant what test to perform and what not to."

When the consultant tried to explain the new way of working compared to the traditional way, many pilot participants pointed out that the company already was successful in the market compared to its competitors. An engineer said:

"Why change while we have so far been very good in the market by relying on our technical competence and the existing way of working?"

According to the statement above and similar statements, it seems that the development teams did not appreciate the initiative's set-up to utilize an external consultant for introduction of new methods. The consultant started to set up a number of questions in order to be able to define the real problem. He tried to ask the development teams what they were doing currently, in order to open their eyes and create a thinking process for the reasoning of the method. But this made the "proud" development teams feel humiliated and they consequently rejected the initiative. The teams felt that the consultant was questioning their way of working, and thus they became negative toward the approach. Further, they believed more in their technical product knowledge for problem-solving than in knowledge of problem-solving methods.

\section{A narrow scope of the initiative}

The RD initiative and pilots included only the implementation of the RD method. However, during the interviews many of the engineers highlighted the existence of 
problems in other processes out of the scope of the initiative, which hindered the implementation of the pilots. One example mentioned was problems in the requirement management process in the pilot projects. Not all requirements were clearly described in the projects and communicated to them from the beginning, prior to the design activities and pilot initiation. The requirements of each design solution area were distributed to the development teams late in the process, and the final requirements were given to the teams when they already had a solution ready.

A lead engineer in a pilot team was quoted:

"... and I doubt even if the needs, targets and the applications I have got from the product planning department are fully reflecting end-customer needs, and I am afraid of being blamed later on when the customer claims reach us."

Another engineer, who was negative toward RD tools and their focus, said:

"...do you think making a lot of effort to design a robust product with $R D$ tools is more important than our challenge today concerning the communication of the requirements from the product planning department to us? We can design a robust product but we cannot guarantee that the designed product is what the market needs. This is where I prioritized my activities today in the project to ensure my deliveries."

As another example in the pilot cases, one question was repeated several times: the challenge of "how to balance the targets concerning quality, feature, cost and delivery time $^{13}$ ”. This is mainly the question of the project priorities which affects many decisions concerning the priorities of deliverables through the development phases. In the case of the pilots, the development teams believed that the project's scope and priorities had been identified by management, but these were not distributed and communicated to them ${ }^{14}$. It happened that engineers said:

"It is not clear to us which of the deliverables should be focused on while we are making decisions e.g. for concept evaluation or supplier selection."

Another engineer clarified:

"In Pugh activity and concept selection, we faced some criteria concerning our deliverables, but in order to do the trade-offs we need to know the importance of our deliverables, so it is not possible to use a tool and get benefit from it while we don't have the project priorities' input to the tool implementation."

It seemed that the existing problems in processes outside the initiative's scope worked as an obstacle to the implementation, e.g. lack of a suitable approach for 'customer requirement management', and of a settled approach for product projects' scope identification and communication.

\footnotetext{
${ }^{13}$ The four standard categories of the projects' deliverables in the company.

${ }^{14}$ It should be stressed that this is a belief that top management themselves know the project's scope and priorities - which, however, is not proven.
} 


\section{The engineers were not convinced that the tools would solve the problems}

The pilot cases were initiated by introducing the RD method tools in relation to the described problems in each case as well as to the initiative's main objective. However, the development team hardly believed that the tools introduced would be sufficient to reach the objective of the initiative. One engineer stated that:

"The tools themselves were interesting, but how they should be used in the real application at our company processes did not become clear to me. I could say they were just nice ideas...

...I could not see the benefits of the tools for our problems in the long term. I believe that my manager could not see it either. I didn't face any argument on why we should follow the tools."

They were not convinced that the stated problems could be solved through the implementation of the tools presented by the consultant. The tools might help, but the development teams felt that there were many other important issues to be focused on first, to be able to solve the problems. One engineer was quoted as saying:

"Today we have a communication problem concerning the interface with other development teams. We in the design team could implement the presented tools and they might support us a little, but they won't solve the problem."

In the case of the RD initiative, the primary objective was to introduce the RD method in order to reduce the risk of quality problems, taking for granted that the method would solve the problems. However, the development teams that were being trained to use the RD method could not see how the RD method would contribute to solving the problems.

\section{Poor integration into projects' daily activities}

In the initiative it was recognized that in some cases the resources were not allocated for following the pilot cases according to the plan. The management strategies and priorities for resource allocations were not aligned with the initiative's way of working. In some cases the resources for early simulation in DoE were not assigned or were assigned late. Thereby the pilot cases were faced with decreased motivation among the team members. An engineer said:

"Of course we were (primarily) supposed to deliver to our management concerning the project (more than commitment to the pilot)."

In some cases, management asked the people involved to prioritize other meetings instead of the RD training workshops. It also happened that the pilot meetings were cancelled due to other priorities requested by management.

For some participants the pilots were seen as an extra burden separated from the actual project activities. It was said that:

"We are very squeezed in our time plan and we did not have time to do what the consultant requested."

Another said:

"We were given a test plan while we had already a test plan which we were quite confident about." 
They had the opinion that RD pilots took a lot of effort away from their ordinary job. This means that they had perceived the method introduced by the consultant as something parallel to their daily activities, and not suitable to integrate into the ordinary daily job and framework. The pilot team members were also unaware of how to use the method within their actual project time plan.

Concerning the consultant's way of working as a coach and expert, the people involved said that they needed more support than the contracted initial two weeks. After those weeks the consultant continued to provide support through net-meetings and e-mails, but this was not enough according to the involved engineers. Instead they asked for more live coaching with direct involvement. One engineer who was more positive concerning the initiative still commented:

"We had a plan in front of us but none of us really understood why and how to do it."

It seems that the arrangement with distance supervision was not sufficient and contributed to the fading out of the initiative due to lack of live on-the-job training and coaching.

\section{Lack of prerequisite statistical knowledge}

During the pilot projects it was also realized that the statistical knowledge which was expressed as a prerequisite for the RD method was not in place to run the pilot projects.

One engineer commented:

"The presented statistics seemed to be more suitable for advanced engineering and research projects, not a suitable approach for daily project activities in product development; it was more academic."

The engineers could not fully grasp the tool and its corresponding statistical analysis, and therefore they had difficulties accepting the method and committing themselves to be engaged and involved in the pilot.

\section{Culture of fire-fighting}

During the pilot applications in the company, there was not enough motivation for preventive actions. As was told by an engineer, referring to the cultural problem of preventive work:

"...every individual engineer might think that good fire-fighters become visible, so why focus on something which could not be visible immediately?"

Besides the motivation, the will of projects to spend money in early phases was not secured. One engineer said during the interview :

"I am not sure if the project managers are willing to spend money in early phases for preventive jobs."

The reason and urgency to change from fire-fighting mode to a more proactive mode was not clear to the people involved in the pilots, and was not fully understood and supported by middle management either. 


\section{Discussion}

Naturally, there are many potential advantages in using an external consultant in introductions of new initiatives. However, the outcome depends to a large extent on how the external consultant is used and to what extent the initiative is part of what is perceived as central by the members of the organization. In the case of the RD initiative, it was not perceived very well in the company and the result of the initiative was limited, mainly due to the obstacles presented above. Some of the main issues identified will be discussed below.

\section{Improving a successful company}

The Volvo Group had been successful in the marketplace during a long period of time, relying on the competence of its engineers who 'know the product best'. This contributed to a belief internally that technical product knowledge is the most important issue in problem-solving, rather than specific problem-solving methods. The RD initiative aimed to change the existing way of working in the same development teams that for years had contributed to the success of Volvo, but the development teams could not see any obvious reason for change.

In general, it can be very difficult to change a successful company with employees who are proud to have contributed to their corporation's success in the marketplace and who believe in their own abilities and approaches to problem-solving (Tushman \& O’Reilly III, 1997). Therefore one should be even more careful in introducing new and unfamiliar tools and methods in such environments. In the RD initiative, the company's previous success was not considered as a potential inhibiting factor which could work against the 'tool-pushing approach' of the initiative.

Many change initiatives neglect to deal with their company's existing beliefs or organizational paradigm (Argyris \& Schön, 1996). The importance of creating an awareness of the need for change and the consequences of staying the same, i.e. increasing the 'survival anxiety', has been emphasized by various scholars (Schein, 1996). Put into a Volvo context this means that in order to become interested in learning new problem-solving methods, the Volvo engineers need to become aware that their traditional working methods would not be sufficient for Volvo to stay competitive in the future. But there is also a need of providing a clear picture of what the change would lead to and what kind of impact it might have for each individual as well as indicating a plausible road ahead, i.e. lowering 'learning anxiety' (Schein, 1996). Here, Schein's (2006) advice would be to use the strength of the company culture to change those elements that have become dysfunctional, i.e. to build on Volvo's strengths and further reinforce its work processes by integrating robust design.

\section{The problem definition phase}

The RD initiative was based on the result of a diagnosis by the top management in the company; yet the problems that the top management had identified, and their link to the objectives and scope of the initiative, were not clear to other members of the organization. Thus the development teams could not grasp the initiative's purpose and its benefits for the company and for the individuals in product development. For them, the initiative seemed more like an application of a set of tools pushed into the organization from the top, instead of a problem-solving initiative. This perception was also reinforced by the RD initiative's lack of focus on the problems that the 
development teams themselves had experienced, e.g. in the customer requirement management process ${ }^{15}$. Hence, the problem diagnosis at the top management and at the development engineer levels were not aligned, which can be seen as a weakness in the problem definition phase. As a result there was no sense of urgency for the implementation of the initiative and it remained loose in the organization.

Every change initiative gets its credibility through its problem definition phase. When the objectives and scope of an initiative are based on a shared view of identified problems ${ }^{16}$, then it makes sense for the employees to be part of the change journey. A shared diagnosis will also overcome at least part of the resistance through a better understanding of the reasoning behind the initiative.

The focus of the initiative; tools vs. learning focus

The RD initiative, with an external consultant pushing tools and a predefined solution to proud development engineers, did not work. The primary objective of the initiative was to introduce the RD method in order to reduce the risk of quality problems, taking for granted that the method would reduce the risk of quality problems. However, the pilot teams did not fully believe in the assumption, as they could not see how the RD method would contribute to this objective. They had not utilized the RD method before and still they had delivered competitive products to the market and made their company successful. Part of their hesitation was due to the above objective for the initiative.

With a more humble scope, letting the pilot teams test new ways of working, the teams might have been more positive to the initiative. There was a need for localizing the $\mathrm{RD}$ method by creating learning processes around identified problems, in order to develop work approaches based on local practices and potential new tools/methods. ${ }^{17}$ In this context, robust design could be most valuable, emphasizing the importance of 'variation awareness' and robustness (Arvidsson \& Gremyr, 2008) - where the development teams, focusing on variation and on understanding its consequences, could build, test and learn new ways of working and consciously improve their practices. This kind of systematic reflection, typically done in pilot projects, provides the input for a gradual internal standardization of both the content and the implementation process (Alänge \& Steiber, 2011).

The middle management role

In the RD initiative, the involvement of middle management (all levels of managers between the top leadership and the development teams) was not strong enough (as can be seen in Figure 1). As the middle managers did not lead the initiative, they did not act to create a context in which the development teams were stimulated to reflect upon their existing way of working in order to become open to learn new ways. Instead the external consultant took such a role, which resulted in lack of buy-in to the idea of the

\footnotetext{
${ }^{15}$ This is an area where one of the practices identified by Hasenkamp et al. (2009) could be helpful, 'Focus on the customer'. This practice concerns a systematic way of identifying key customer characteristics and translating them into quality characteristics that RDM aims at making insensitive to noise factors.

${ }^{16}$ Dahlgaard et al. (2011) emphasize the importance of involving people in identifying problems, root causes and needed actions as when change is more profound, "It requires that people understand what to change and why."

${ }^{17}$ Hasenkamp et al. (2007) provide guidelines for when RD tools potentially could be useful.
} 
initiative. Moreover, as the middle management was not fully involved, the initiatives did not have access to committed resources - such as technical systems, software, time, money and people. Lack of committed resources can easily jeopardize the success of an initiative.

Successful change programs, in large corporations, typically start closer to the bottom line of the organization than in corporate staffs (Beer et al., 1990). As middle managers are closer to employees who are supposed to execute the change, they have more power to influence and get the initiative accepted among the employees, and to provide the resources needed, when they are needed. With a lack of middle management involvement ${ }^{18}$, the $\mathrm{RD}$ initiative remained external to the development teams - and this could be a factor that contributed to resistance to the initiative. In the case of the RD pilots, top management took the initiative to contract the external consultant and initiate training; and although middle managers were invited to a seminar given by the external consultant, and were consulted in the selection of pilot projects, there was still a lack of real 'buy-in' and involvement in the process. This emphasizes the difficulty of initiating change processes from above, and the need for a thorough anchoring of change processes initiated from above - where middle management is provided with the opportunity of assuming ownership of the change process.

As in all change processes, leaders need to change their priorities and behaviour in line with a decision to make robust design a natural and integrated part of work for development engineers. It is in this context of changing behaviour and work approach among middle managers and development engineers that the RDM practices suggested by Hasenkamp et al. (2009) can become an effective means to an improved practical use of robust design methodology.

The role of internal vs. external consultants

There are many potential advantages in using an external consultant in introductions of new initiatives, not least because an experienced consultant can be specialized in a certain competence area and draw on experiences from several other organizations. However, external consultants do not have insights into the local context of an organization, which could negatively affect an implementation process and create legitimacy problems (Schein, 1996). Beer and Nohria (2000) even argue that external consultants can only help an organization to help itself, e.g. to coach the middle managers on how to define problems, be change leaders and develop organizational capabilities.

To better support the middle management, an external consultant could also train internal consultants for implementation. Unfortunately, many organizations do not recognize the value of internal consultants and their capability to influence the bottom line organization, so they rely solely on experienced external consultants who cannot be as effective for the internal implementation (Scott \& Hascall, 2002). In the RD initiative it was planned that Project Quality Managers should assume the role of internal consultants for the implementation of the RD method. However, they neither were sufficiently knowledgeable and trained for the initiative's purpose, nor got

\footnotetext{
${ }^{18}$ Alänge (1992, p.162) pointed out "that the role of first line supervisors and middle management is crucial to the survival of the QC concepts".
} 
mandates from the middle management to support and coach the pilot projects or to assist in integrating the initiative in development project activities. Thus they acted very passively through the whole initiative, participating more as observers than by building long-term relationships with pilot teams and acting as a "pair of hands" to facilitate their learning process. However, properly trained internal consultants given appropriate conditions could assume an important role as facilitators to support groups changing their work processes, including using robust design.

\section{Conclusion}

What can be learned from Volvo's first initiative to introduce the RD method, which turned out to be less than successful? From a change perspective, several ingredients seemed to be right. Top management had identified a clear need for robust design, and an experienced international consultant was contracted for introducing the RD method and supporting pilot projects. However, the RD method did not gain acceptance as a natural practice in daily product development activities, and the initiative as a whole became a failure.

Part of the explanation for the resistance to accepting new methods from the outside can be found in development engineers' rightful pride in having contributed to their corporation's success in the marketplace during a long period of time. Yet other factors also influenced the outcome of the pilot projects. As the RD initiative came from top management, and an external consultant got the assignment to function as a change agent, the initiative in the pilot projects remained external to the development engineers and their immediate managers.

Important learning was that in the Volvo context, an initiative with 'tool-pushing' and a predefined solution introduced by an external consultant did not work. It is also probable that tool-pushing would meet resistance even if the tools were imposed by internal units. Although top management saw the introduction of RD methods as a solution for identified quality problems, this view was not shared by the development engineers or, still more detrimentally, by middle management. This shows the need for a modified approach based on a stronger involvement of middle management and development engineers in problem analysis and in prioritizing activities/resources, if it is agreed that robust design is the approach selected for solving quality problems in the long term. In other words, there is a need to localize the initiative by creating learning processes in which robust design principles can become a natural part of work practices.

\section{References}

Alänge, S. (1992). What role do QC-circles play in Sweden. Total Quality Management, 3(2), 157-163.

Alänge, S., Steiber, A. (2011). Diffusion of Organisational Innovations: An empirical test of an analytical framework. Technology Analysis \& Strategic Management, 23(8), 881-897. 
Antony, J. (2002). Robust Design in new product development process: a neglected methodology in UK manufacturing organization. International Journal of Productivity and Performance Management, Work Study, 53(2), 81-84.

Araujo, C. S., Benedetto-Neto, H., Campello, A. C., Segre, F. M., Wright, I. C. (1996). The utilization of product development methods: A survey of UK industry. Journal of Engineering Design, 7(3), 265-279.

Argyris, C., Putnam, R., McLain Smith, D. (1985). Action Science: Concepts, Methods, and Skills for Research and Intervention. San Francisco: Jossey-Bass.

Argyris, C., Schön, D. (1996): Organizational Learning II: Theory, Method, and Practice. MA: Reading Addison-Wesley ( $1^{\text {st }}$ edition published in 1978).

Arvidsson, M., Gremyr, I., Johansson, P. (2003). Use and knowledge of Robust Design - A Survey of Swedish industry. Journal of Engineering Design, 14(2), 1-15.

Arvidsson, M., Gremyr, I. (2008). Principles of Robust Design Methodology. Quality and Reliability Engineering International, 24(1), 23-35.

Beer, M., Eisenstat, R. A., Spector, B. (1990). Why Change Programs Don’t Produce Change. Harvard Business Review, Nov-Dec, 68(6), 158-166.

Beer, M., Nohria, N. (2000). Breaking the code of change. Boston, MA: Harvard Business School Press.

Coch, L., French, J.R.P. (1948). Overcoming Resistance to Change, Human Relations, 1(4), 512-532.

Coghlan, D., Brannick, T. (2005). Doing Action Research in Your Own Orgaization. $2^{\text {nd }}$ ed., London: Sage Publications.

Dahlgaard-Park, S.M. (2011). The quality movement: where are you going?. Total Quality Management \& Business Excellence, 22(5), 493-516.

Dahlgaard, J.J., Pettersen, J., Dahlgaard-Park, S.M. (2011). Quality and lean health care: a system for assessing and improving the health of healthcare organisations. Total Quality Management \& Business Excellence, 22(6), 673-689.

Dent, E.B., Goldberg, S.G. (1999). Challenging “Resistance to Change”. Journal of Applied Behavioral Science, 35(1), 25-41.

Dubois, A. \& Gadde, L-E. (2002). Systematic combining: an abductive approach to case research. Journal of Business Research, 55(7), 553-560.

Gremyr, I., Arvidsson, M., Johansson, P. (2003). Robust Design Methodology: Status in the Swedish manufacturing industry. Quality and Reliability Engineering International, 19(4), 285-293.

Gremyr, I., Hasenkamp, T. (2011). Practices of robust design methodology in practice. The TQM Journal, 23(1), 47-58.

de Guerre, D.W. (2002). Doing Action Research in One's Own Organization: An Ongoing Conversation Over Time. Systemic Practice and Action Research, 15(4), 331-349.

Hasenkamp, T. (2009). Designing for Robustness. PhD-thesis, Quality Sciences, Dept. of Technology Management and Economics, Chalmers University of Technology, Gothenburg. 
Hasenkamp, T., Adler, T., Carlsson, A., Arvidsson, M. (2007). Robust Design Methodology in a Generic Product Design Process. Total Quality Management \& Business Excellence, 18(4), 351-362.

Hasenkamp, T., Arvidsson, M., Gremyr, I. (2009). A review of practices for robust design methodology. Journal of Engineering Design, 20(6), 645-657.

Hino, S. (2006). Inside the mind of Toyota: management principles for enduring growth. NY: Productivity Press.

Kotter, J.K., Schlesinger, L.A. (1979/2008). Choosing Strategies for change. Harvard Business Review, July-August 2008, 130-139.

Merriam, S.B. (1988). Case study research in education: A qualitative approach. San Francisco: Jossey-Bass.

Moosa, K., Sajid, A. (2010). Critical analysis of Six Sigma implementation. Total Quality Management \& Business Excellence, 21(7), 745-759.

Mörup, M. (1993). Design for Quality. PhD-thesis, Institute for Engineering Design, Technical University of Denmark, Lyngby.

Phadke, M. (1989). Quality Engineering using robust design. New Jersey: Prentice Hall.

Saitoh, K., Yoshizawa, M., Tatebayashi, K., Doi, M. (2003). A study about how to implement quality engineering in research and development (Parts I \& II). Journal of Quality Engineering Forum, 11(3), 476-483.

Schein, E. (1996). Kurt Lewin's Change Theory in the Field and in the Classroom: Notes Toward a Model of Managed Learning. Systems Practice, 9(1), 27-47.

Schein, E. (2006). From Brainwashing to Organizational Therapy: A Conceptual and Empirical Journey in Search of 'Systemic' Health and a General Model of Change Dynamics. A Drama in Five Acts, Organization Studies, 27(2), 287-301.

Scott, B., Hascall, J. (2002). Inside or Outside: The Partnerships of Internal and External Consultants. In N. Delener \& C. Ghao (Eds.), International conference readings book. Rome: Global Business and Technology Association.

Taguchi, G. (1986). Introduction to quality engineering - Designing quality into products and processes. Tokyo: Asian Productivity Organization.

Thornton, A.C., Donnelly, S., Ertan, B. (2000). More than Just Robust Design: Why Product Development Organizations Still Contend with Variation and its Impact on Quality. Research in Engineering Design 12, 127-143.

Tushman, M., O’Reilly III, C. (1997). Winning through Innovation: A Practical Guide to Leading Organizational Change and Renewal. Boston, MA: Harvard Business School Press.

Ulrich, K.T., Eppinger, S.D. (2004). Product Design and Development. New York: McGraw-Hill.

Yin, R.K. (2003). Case study research: Design and methods ( $3^{\text {rd }}$ ed.). Thousand Oaks,CA: Sage. 